\title{
Fixed Bed Adsorption of Drugs on Silica Aerogel from Supercritical Carbon Dioxide Solutions
}

\author{
Giuseppe Caputo \\ Dipartimento di Ingegneria Industriale, Università degli Studi di Salerno via Giovanni Paolo II, 132-84084 Fisciano, Italy \\ Correspondence should be addressed to Giuseppe Caputo; gcaputo@unisa.it
}

Received 16 March 2013; Accepted 5 June 2013

Academic Editor: Jaime Wisniak

Copyright (C) 2013 Giuseppe Caputo. This is an open access article distributed under the Creative Commons Attribution License, which permits unrestricted use, distribution, and reproduction in any medium, provided the original work is properly cited.

\begin{abstract}
Supercritical adsorption coupled with the high adsorption capacity of silica aerogel allows the preparation of a new kind of delivery systems of poor water soluble drugs. In order to overcome drawbacks of conventional techniques where the use of liquid solvents can cause the fracture of aerogel porous structure, in this work a new adsorption process of drugs from a supercritical mixture is proposed. Adsorption takes place from a fluid solution of the drug in supercritical $\mathrm{CO}_{2}$ and ethanol as cosolvent. A fixed bed adsorption plant has been developed to allow fast mixing of fluid phase and effective contact in the adsorption column. The use of ethanol as cosolvent allows to overcome the limitation of supercritical adsorption due to low solubility of many drugs in supercritical $\mathrm{CO}_{2}$. Adsorption isotherms were measured for one-model substance, nimesulide, at $40^{\circ} \mathrm{C}$, and breakthrough curve was experimentally obtained. The drug loading of the drug into silica aerogel was up to $9 \mathrm{wt} \%$. The drug composite was characterized using scanning electron microscopy, and release kinetics of the adsorbed drug were also evaluated by in vitro dissolution tests. The dissolution of nimesulide from loaded aerogel is much faster than dissolution of crystalline nimesulide. Around $80 \%$ of nimesulide dissolves from the aerogel within 6 minutes, whereas dissolving $80 \%$ of the crystalline drug takes about 90 min.
\end{abstract}

\section{Introduction}

The poor water solubility of some drugs limited their bioavailability. A fast dissolving system can be defined as a dosage form for oral administration, which, when placed in mouth, rapidly dispersed or dissolved increasing compliance and efficacy of the therapy. Fast dissolving and fast dispersing drug delivery system may offer a solution to these problems. A possible approach for ensuring maximum bioavailability is the increase of drug dissolution rate and/or solubility. To improve the dissolution rate of drugs, different techniques have been developed [1]. The most common approach is based on particle size reduction that can be achieved by processes based on micronization or nanosuspension. In the field of supercritical fluids, various promising techniques of micronization of drugs and excipients with supercritical carbon dioxide $\left(\mathrm{SC}-\mathrm{CO}_{2}\right)$ have been developed $[2,3]$, and also the use of water solvent and the less-expensive supercritical nitrogen is being explored [4-6]. An alternative way to improve the availability of a drug is its dispersion on a biocompatible substrate [7]. Silica-based materials used as substrate are widely employed as additives, free flow agents, and drug carriers also in commercial products. A special class of silica materials is silica aerogels (SA). They are low-density nanoporous solids with a fine open-pore structure that exhibits unique properties, such as high porosity (90-99\%), high surface area $\left(400-1000 \mathrm{~m}^{2} / \mathrm{g}\right)$, and extremely low density $\left(0.003-0.15 \mathrm{~g} / \mathrm{cm}^{3}\right)$. These properties allow them to be used as host matrix for drug delivery. Silica aerogels were recently shown to be a potential candidate for oral drug delivery systems [8-10]. A promising method to adsorb a drug into porous substrates is supercritical (SC) deposition or adsorption $[8,9,11-13]$. Essentially, the process involves the dissolution of the active molecules in a supercritical fluid and the impregnation of the substrate by its exposure to this solution. Supercritical carbon dioxide $\left(\mathrm{SC}-\mathrm{CO}_{2}\right)$ is commonly used due to its relatively good solvent power for various drugs, mild critical temperature $\left(31^{\circ} \mathrm{C}\right)$, low critical pressure (7.4 MPa), and inertness. After the removal of the supercritical fluid (SCF) by expansion, a drug-loaded matrix free of solvent residues is obtained. This method takes advantage of the unique properties of SCFs. Indeed, a SCF possesses a 
unique combination of gas-like and liquid-like properties that can be adjusted by small changes in temperature or pressure.

Low viscosity and high diffusivity of $\mathrm{SC}-\mathrm{CO}_{2}$ allow a rapid equilibration and micropore penetration of the fluid phase within the matrix. SCFs also have zero surface tension that not only facilitates the rapid permeation and diffusion into porous substrates, but also avoids the pore collapse of SA that occurs using organic liquids, due to capillary stresses caused by the liquid-vapour menisci within pores.

Until now, SC adsorption within SA has been studied using simple batch vessels in which SA and active molecules are loaded and equilibrated until equilibrium is reached $[8,9$, $11,12]$. Because pure $\mathrm{SC}-\mathrm{CO}_{2}$ is used as solvent, the maximum amount of active compound that can be loaded on SA is limited by its solubility in SC- $\mathrm{CO}_{2}$ at given condition of temperature and pressure. One way to increase the solubility is the increase of pressure of SC- $\mathrm{CO}_{2}$ as shown in a previous work in the case of nimesulide [12]; an alternative is the use of a compatible and benign cosolvent which increases the solubility of the active compound in the fluid phase. The fluid phase composed by $\mathrm{SC}-\mathrm{CO}_{2}$ and cosolvent must satisfy the condition that the mixture is supercritical at the operating pressure and temperature. Indeed, if a liquid phase is formed, the aerogel structure could be damaged and polluted by the cosolvent.

In this work, the adsorption of a model drug on SA was studied using a new experimental apparatus properly designed for this purpose. The best way to deal with SC-fluid mixture is to use a continuous process in which the fluid phase is continuously pumped in an adsorption column containing the SA matrix. Because, a fundamental stage of the process is the formation of the ternary mixture SC$\mathrm{CO}_{2}$ /organic solvent/active compound, a mixing stage has been provided that allows a fast and effective solubilization of the components.

The new experimental plant has been tested with nimesulide as active compound and ethanol as solvent. Nimesulide has been chosen for comparison purposes because in a previous study [12] its adsorption from pure $\mathrm{SC}-\mathrm{CO}_{2}$ and using a batch mode apparatus was studied. Adsorption isotherm and breakthrough curve of the column at $40^{\circ} \mathrm{C}$ were determined. Loaded SAs were characterized by in vitro dissolution test to study the properties of the composite material and its potentiality for applications.

\section{Materials and Methods}

2.1. Materials. Hydrophilic silica aerogel (SA) in form of monolithic blocks was purchased from Merketech Int. (USA). The nominal density is $0.1 \mathrm{~g} / \mathrm{cm}^{3}$ the surface area is $800 \mathrm{~m}^{2} / \mathrm{g}$, and the mean pore size is about $20 \mathrm{~nm}$. Deposition experiments were performed using cubic blocks of $1 \mathrm{~cm}$ obtained by cutting SA monoliths with a knife. Nimesulide (purity 98\%) was purchased from Sigma-Aldrich Italy. $\mathrm{CO}_{2}$ research grade 4.8 was purchased from SON (Italy). All products were used as received.

2.2. Methods. Samples of the loaded SA were observed by Field Emission Scanning Electron Microscopy (FE-SEM) (LEO 420, USA) operating at $5 \mathrm{kV}$. Crushed fragments of the sample were dispersed on a carbon tab previously stuck to an aluminium stub and coated with gold palladium (layer thickness $250 \AA$ ) using a sputter coater (mod. 108A; Agar Scientific, UK). Several FE-SEM images from different parts of the sample were taken for each run to verify the powder uniformity.

Drug dissolution profiles were obtained with a United States Pharmacopeial Convention (USP) apparatus 2, consisting of Varian 7025 paddle dissolution tester (Varian, Agilent Technologies Italia s.p.a, Italy). All studies were run according to the USP 25 paddle method: $150 \mathrm{rpm}, 900 \mathrm{~mL}$ of dissolution medium, $T=37.2 \pm 0.1^{\circ} \mathrm{C}$, and sink conditions $\left(c<0.2 \mathrm{c}_{\mathrm{s}}\right)$. The adsorbed SA monoliths were coarsely crushed in a mortar and suspended in water. Then, the aqueous solution was continuously pumped to a flow cell in a spectrophotometer, and absorbances were recorded at $396 \mathrm{~nm}$. The composition of the dissolution medium was $0.2 \mathrm{M} \mathrm{KH}_{2} \mathrm{PO}_{4} / 0.2 \mathrm{M} \mathrm{NaOH}$ (ph 7.4) according to USP 25, plus $0.5 \%$ w/v of Tween 80.

\section{Apparatus}

The laboratory plant is described in Figure 1. It is made by 316 stainless steel tested for a maximum pressure of $30 \mathrm{MPa}$ at $200^{\circ} \mathrm{C}$. It mainly consists of two feed lines, used to deliver the $\mathrm{CO}_{2}$ and the liquid solution, and three main vessels: mixer, adsorption column, and separator. $\mathrm{CO}_{2}$, stored in a vessel, is delivered to the mixer by a volumetric pump (P1) (Milroyal tipo MD140G6 M35/J) through a one-way valve $\left(\mathrm{V}^{\prime}-1\right)$ and on/off valve (V4). The head of the pump is cooled by a thermostatic bath $(\mathrm{C})$ to avoid cavitation of $\mathrm{CO}_{2}$. The liquid solution is delivered by a membrane pump (P2) (Lewa, Germany, type LDB) from a graduated cylinder.

The mixer is a stainless steel autoclave (NWA GmbH, Germany) having an internal volume of $100 \mathrm{~mL}$, closed on the bottom and on the top with two finger tight clamps. The top cap holds three $1 / 8$ inch ports. Mixing is provided by an impeller mounted on the top cap and driven by a variable velocity electric motor. The autoclave is heated by thin band heaters $(\mathrm{H})$ (Watlow, USA mod. STB4E3A9) whose thermal control is guaranteed by a PID controller (Watlow, USA). The temperature inside the cylinder is measured by a $\mathrm{K}$ type thermocouple with an accuracy of $\pm 0.1^{\circ} \mathrm{C}$. Pressure is measured by a digital gauge manometer (Parker, USA). Mixer was designed to provide a contacting volume and a residence time sufficient to allow the dissolution of $\mathrm{SC}-\mathrm{CO}_{2}$ in the liquid solution up to the saturation conditions.

The adsorption column is a 316 SS cylindrical vessel with an internal volume of $50 \mathrm{~cm}^{3}$. It is packed with a silica aerogel bed. The pressure inside the column is maintained by a micrometric valve MV2 heated by electric heaters to avoid clocking during $\mathrm{CO}_{2}$ expansion. From the exit of the column the gaseous flow of $\mathrm{CO}_{2}$ and solvent is sent to a gravimetric gas/liquid separator, that is a Pyrex element properly designed for the separation of the solvent from the gas stream. At the inlet port of the separator an impact surface is provided to improve separation. The liquid is collected at the bottom of the cylinder where a probe connected to an UV spectrophotometer allows the continuous measurement of the liquid composition. The separator has been designed 




FIGURE 1: Continuous plant for the adsorption of drugs from supercritical carbon dioxide solutions. P-1, P-2: pumps; C: cooling bath; $\mathrm{V}^{\prime}-1$ : one way valve; V-1, V-2, V-3, V-4, V-5: on/off valve; TW-1: three-way valve, SV-1: security valve; H: heater; F: filter; MV-1, MV-2: micrometric valves; FE: rotameter.

to condense ethanol. At the exit of the separator a rotameter $(\mathrm{FE})$ is used to measure $\mathrm{CO}_{2}$ flow rate.

The design of the separator has been based on the method proposed by Treybal [14]. The input data were liquid density, gas density at given temperature, and their flow rates. The design procedure has been the following: (1) the limiting velocity is calculated on the basis of the ratio between the density of the gas and the liquid; (2) the surface of the separator is calculated from the limit velocity and the volumetric flow rate of the gas; (3) a tentative residence time is assumed and the volume of the separator is calculated.

\section{Results and Discussion}

Supercritical adsorption has been carried out in a continuous mode until saturation of the SA bed is reached. SC- $\mathrm{CO}_{2}$ and a liquid solution (ethanol + nimesulide) after mixing are continuously delivered to the high pressure adsorption column.

Because the phase behavior of the ternary system $\mathrm{CO}_{2} / \mathrm{EtOH} / \mathrm{Nime}$ is not available, our analysis starts from the binary system $\mathrm{CO}_{2} / \mathrm{EtOH}$. The miscibility curve of the binary system $\mathrm{CO}_{2} / \mathrm{EtOH}$ is shown in Liparoti et al. [15]. It is thus assumed that the effect of nimesulide on the phase behavior is negligible. This assumption is reasonable considering the low concentration of nimesulide $(<0,25 \mathrm{wt} \%)$. The temperature and pressure conditions $\left(40^{\circ} \mathrm{C}\right.$ and $\left.10 \mathrm{MPa}\right)$ have been selected considering the following factors: (a) thermolability of the drug; (b) formation of a single fluid phase between $\mathrm{CO}_{2} /$ ethanol/nimesulide verified by direct visual observation of the system behavior in a high pressure view cell. It was verified that at the selected operating conditions nimesulide does not precipitate from fluid phase.

At this condition of temperature and pressure the effect of the weight ratio $\mathrm{CO}_{2} / \mathrm{EtOH}(R)$ on the drug loading has been studied. Experiments have been carried out using SA bed with a $L / D$ of 9.4 and pumping $150 \mathrm{~mL}$ of EtOH solution
TABLE 1: Adsorption data of nimesulide on silica aerogel at different values of the $\mathrm{CO}_{2} / \mathrm{EtOH}$ weight ratio $(R) . W_{\text {nime }}$ is the mass fraction of nimesulide in the solution, time is the duration of the experiment until bed saturation is reached, and Eff is the efficiency of adsorption.

\begin{tabular}{lccccc}
\hline$R$ & $\mathrm{X}_{\mathrm{CO}_{2}}$ & $W_{\text {nime }}$ & Loading, \% & Time & Eff, \% \\
\hline 7.2 & 0.88 & 0.000047 & 0.48 & 94 & 92.6 \\
3.4 & 0.78 & 0.000856 & 1.0 & 75 & 93.3 \\
1.5 & 0.61 & 0.0015 & 2.8 & 50 & 96.1 \\
0.9 & 0.48 & 0.00197 & 5.4 & 60 & 92.3 \\
0.6 & 0.38 & 0.00245 & 8.9 & 37 & 94.8 \\
\hline
\end{tabular}

with nimesulide concentration of $3 \mathrm{mg} / \mathrm{mL}$. All the operating points comprised between 0.38 and $0.88 \mathrm{CO}_{2}$ mole fraction fall in the one-phase region of the phase diagram. In Table 1 the obtained drug loadings are reported.

The variation of nimesulide loading on SA with respect to the concentration of nimesulide in the fluid solution is reported in Figure 2. Because each experiment has been carried out for a time corresponding to the saturation of the bed, loading represents the maximum quantity of nimesulide that can be absorbed on SA at the given conditions. As a consequence, the curve of Figure 2 represents the absorption isotherm of nimesulide on $\mathrm{SA}$ at $40^{\circ} \mathrm{C}$.

As expected, the loading of nimesulide on SA increases with increasing concentration of nimesulide in the fluid phase. The maximum loading obtained is $8.85 \mathrm{wt} \%$, corresponding to $227.7 \mathrm{mg}$ of nimesulide adsorbed in the bed. Brunauer et al. [16] classified the isotherms that are convex upward throughout (type I) as "favorable" to uptake of solute, whereas the ones that are concave upward throughout (type III) as "unfavorable" to uptake of solute. According to this classification, the isotherm obtained at $40^{\circ} \mathrm{C}$ is favorable.

These data must be compared with the loading of nimesulide on SA reported by Caputo et al. [12] obtained using pure $\mathrm{CO}_{2}$ as solvent. At $40^{\circ} \mathrm{C}$, the maximum loading was 




Figure 2: Adsorption isotherm for nimesulide on silica aerogel at $40^{\circ} \mathrm{C} / 10 \mathrm{MPa}$.

merely 1.4\%, six times lower than that obtained using EtOH as cosolvent. Moreover, adsorption with pure $\mathrm{CO}_{2}$ was carried out at a much higher pressure $(22.5 \mathrm{MPa})$ to increase the solubility of nimesulide.

From Table 1 it is clear that an increase of ethanol fraction increases the nimesulide loading. This result is due to two concomitant effects: (a) increase of the concentration of nimesulide in the fluid phase; (b) the competitive adsorption of $\mathrm{CO}_{2}$ on $\mathrm{SA}$ is reduced and more adsorption sites are available for nimesulide molecules.

4.1. Breakthrough Curve. The most important criterion in the design of fixed-bed adsorption systems is the prediction of column breakthrough curve which determines the operating life of the bed and regeneration time. When the fluid phase starts flowing in to the bed, the top of the adsorbent in contact with the gas stream quickly adsorbs the solute during first contact. The gas stream leaving the bed is practically free from the solute. As the volume of fluid getting from the bed increases, an adsorption zone of mass transfer gets defined. In this zone, adsorption is complete and it moves downwards through the bed in relation to time until the breakthrough occurs. When this zone reaches the end of the bed, the solute cannot be adsorbed any longer. This moment is called "breakpoint". The plot obtained after this point gives the concentration history and is called breakthrough curve. When the mass transfer zone leaves the bed, the bed is completely saturated, adsorption does not occur, and the outlet stream has the same concentration as one enters.

The breakthrough curve for the adsorption of nimesulide on $\mathrm{SA}$ at $40^{\circ} \mathrm{C}$ and $10 \mathrm{MPa}$ is shown in Figure 3. This figure shows the relative effluent concentration against the elution time. The general pattern of the breakthrough curve was as expected. The effluent concentration first increased gradually and then increased sharply before reaching the value of the inlet concentration.

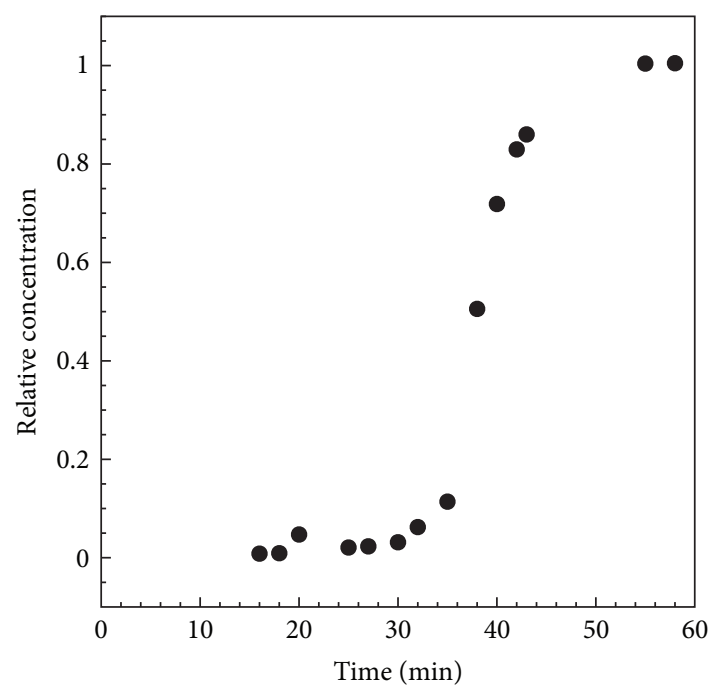

FIGURE 3: Breakthrough curve for adsorption of nimesulide on silica aerogel bed from a stream of $\mathrm{CO}_{2}$ and ethanol at $40^{\circ} \mathrm{C}$, flow rate $=$ $6.89 \mathrm{~mL} / \mathrm{min}, X_{\mathrm{CO}_{2}}=0.378, C_{0 \text { nime }}=0.00174 \mathrm{mg} / \mathrm{mL}$, bed $L / D=$ 9.7 .

The starting point of the curve is shifted of $15 \mathrm{~min}$. This time corresponds to the dead time of the process due to residence time of the fluid phase in the mixer. After $35 \mathrm{~min}$ the concentration of nimesulide in the effluent stream starts to increase significantly $(0.114 \mathrm{mg} / \mathrm{mL})$. This point, corresponding to $10 \%$ of inlet concentration, can be assumed as breakpoint. Indeed, after this time the concentration increased sharply and reached a value of $50 \%$ of the inlet concentration after only 3 minutes. 38 min represents the apparent half-time of the bed. Taking into account the dead time of the plant, the real half-time is 23 minutes.

4.2. Mass Balance. In the transition regime all the solute fed to the column is used to saturate the bed. So the mass balance can be written as

$$
\mathrm{IN}=\mathrm{ACC}
$$

with

$$
\begin{gathered}
\mathrm{IN}=Q C_{0}\left(t^{*}-t_{0}\right), \\
\mathrm{ACC}=\left(W^{\mathrm{sat}}-W_{0}\right) \rho_{\mathrm{bed}} S L,
\end{gathered}
$$

where $Q$ is the volumetric flow rate of the fluid phase ( $\mathrm{mL} / \mathrm{min}), C_{0}$ is the concentration of adsorbate in the fluid phase $(\mathrm{g} / \mathrm{mL}), t^{*}$ is the ideal half-time, $t_{0}$ is the mixing time, $W^{\text {sat }}$ is the saturation concentration of adsorbate in the solid phase $\left(\mathrm{mg}_{\text {ads }} / \mathrm{mg}_{\text {sol }}\right), W_{0}$ is the concentration of the adsorbate in the solid phase at time $t_{0}, \rho_{\text {bed }}$ is the density of the bed $\left(\mathrm{g} / \mathrm{cm}^{3}\right)$, and $S$ and $L$ are the cross-section and the length of the bed, respectively.

The mass balance is thus

$$
Q C_{0}\left(t^{*}-t_{0}\right)=\left(W^{\text {sat }}-W_{0}\right) \rho_{\text {bed }} S L
$$






(a)

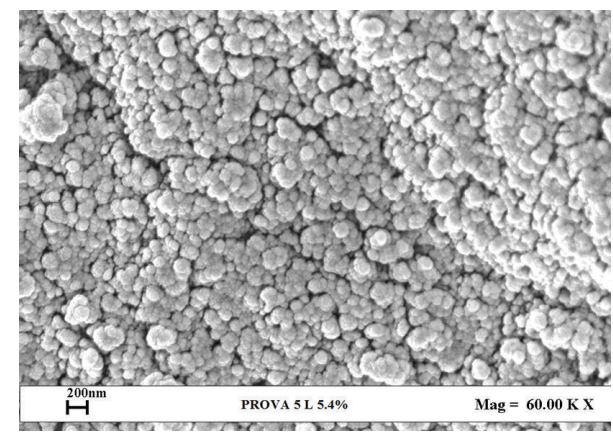

(c)



(b)



(d)

Figure 4: FE-SEM photographs of (a) not treated SA and SA samples loaded with different amount of nimesulide: (b) $1.0 \mathrm{wt} \%$, (c) $5.4 \mathrm{wt} \%$, (d) $8.9 \mathrm{wt} \%$.

from which

$$
\left(t^{*}-t_{0}\right)=\frac{\left(W^{\text {sat }}-W_{0}\right) \rho_{\text {bed }} S L}{Q C_{0}}
$$

by substituting the following values $W^{\text {sat }}-W_{0}=0.0885$, $\rho_{\text {bed }}=0.1 \mathrm{~g} / \mathrm{cm}^{3}, S=2.0096 \mathrm{~cm}^{2}, L=15 \mathrm{~cm}, Q=$ $6.89 \mathrm{~mL} / \mathrm{min}, C_{0}=0.00174 \mathrm{~g} / \mathrm{mL}$, an half time of $37.23 \mathrm{~min}$ is obtained a very good agreement with $38 \mathrm{~min}$ obtained experimentally.

4.3. Adsorption Efficiency. The efficiency of the adsorption is one of the main parameters of the process. It is an expression of the quantity of drug adsorbed with respect to the drug fed to the column:

$$
\mathrm{Eff} \%=\frac{\text { nime }_{\text {ads }}}{\text { nime }_{\text {fed }}} \times 100
$$

with

$$
\text { nime }_{\mathrm{fed}}=C_{0} \times \mathrm{Q} \times\left(t^{*}-t_{0}\right)
$$

by substituting the following values, related to experiment at $R=0.6$ (see Table 1): $Q=6.89 \mathrm{~mL} / \mathrm{min}, C_{0}=1.74 \mathrm{mg} / \mathrm{mL}$, $t^{*}-t_{0}=20 \mathrm{~min}$, a value of $240 \mathrm{mg}$ of nimesulide is obtained. Thus, the efficiency is

$$
\mathrm{Eff} \%=\frac{227.7}{240}=94.8 \% .
$$

Very similar values were obtained for other experiments.
4.4. Characterization of Silica Aerogel after Adsorption. Silica aerogel samples were analyzed by FE-SEM to observe the morphology of the material before and after loading. FE-SEM images taken at the same magnification (60 K magnification) for samples obtained at $1,5.4$, and $8.9 \mathrm{wt} \%$ are reported in Figure 4. Also an FE-SEM image of SA before loading is reported.

FE-SEM images reveal that all samples have the same morphology and no nimesulide crystals were formed on the SA surface also at the higher loading. The presence of nimesulide within SA matrix is clearly revealed by Energy Dispersive X-ray spectroscopy (EDX) spectrum. In Figure 5 EDX of SA sample adsorbed at $5.4 \mathrm{wt} \%$ is shown. The spectrum contains Si peak characteristic of the aerogel and S peak characteristic of nimesulide. Therefore, we can conclude that the drug is adsorbed on the interior of the pores of SA at molecular level.

We studied also the dissolution rate of the drug in vitro. Solution of phosphate buffer at $\mathrm{pH}=7.4$ was chosen as dissolution medium following the recommendation of US Pharmacopeia. The dissolution profile of the drug from the powdered loaded aerogel was compared with that of the pure crystalline drug. Release kinetics are shown in Figure 6. The dissolution of nimesulide from loaded aerogel is much faster than dissolution of crystalline nimesulide. Around $80 \%$ of nimesulide dissolves from the aerogel within 6 minutes, whereas dissolving $80 \%$ of the crystalline drug takes about $90 \mathrm{~min}$. Thus, the use of hydrophilic aerogels as a carrier promotes fast release of the drug. This effect can be explained by both an increase of specific surface area of the drug adsorbed 




FIGURE 5: EDX spectrum of nimesulide/silica aerogel.

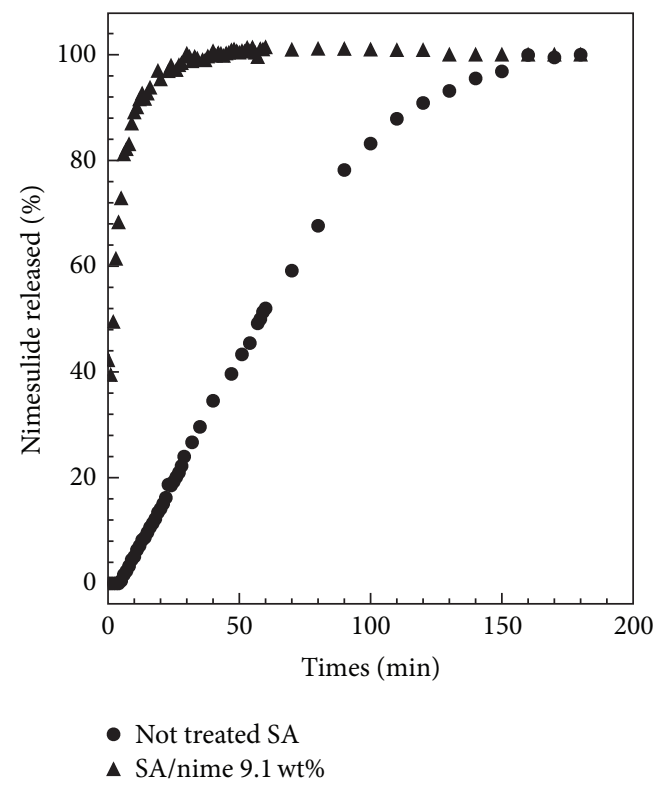

FIGURE 6: Release kinetics of nimesulide in buffer phosphate at $\mathrm{pH}=$ 7.4 .

on the aerogel and its noncrystalline structure in this state. In the case of the crystalline drug, even with a very small particle size, the crystal should be destroyed before the drug can be actually dissolved. If the drug is adsorbed on the aerogel, this step is eliminated and the dissolution process is accelerated. Another important effect is the partial collapse of aerogel structure in water. Hydrophilic aerogels are rapidly wetted with water, so the drug molecules are surrounded with water allowing a fast dissolution of drugs [8].

\section{Conclusions}

In this study, it was demonstrated that the supercritical fluid adsorption is an effective way to incorporate low water soluble drugs into a microporous silica aerogel.

The use of a fixed bed adsorption column fed with a supercritical $\mathrm{CO}_{2}$ solution with ethanol cosolvent allows to obtain a pure drug delivery system at high drug content. Indeed, it was possible to prepare SA samples containing up to $9 \mathrm{wt} \%$ of nimesulide. Moreover, the process is highly efficient in terms of quantity of drug adsorbed with respect to the drug fed to the column (>94\%). With respect to conventional techniques that use liquid as eluent, $\mathrm{SC}-\mathrm{CO}_{2}$ offer the advantage to preserve the $3 \mathrm{D}$ porous structure of the aerogel. Indeed, low viscosity and high diffusivity of $\mathrm{SC}-\mathrm{CO}_{2}$ (or SC-mixtures) coupled with zero surface tension allow the rapid permeation and diffusion into aerogel micropores but also avoid the pore collapse of SA that occurs using organic liquids, due to capillary stresses caused by the liquid-vapour menisci within pores.

The SA/nimesulide composite has an enhanced dissolution rate that can be explained by both the increase in the specific surface area of the adsorbed drug and its noncrystalline structure in the formulation.

One limitation of the proposed process is related to the high cost associated with high-pressure plant when compared to wet processes at atmospheric pressure. However, results encourage the development of industrial application of the proposed process.

\section{References}

[1] S. Pinnamaneni, N. G. Das, and S. K. Das, "Formulation approaches for orally administered poorly soluble drugs," Pharmazie, vol. 57, no. 5, pp. 291-300, 2002.

[2] P. York, U. B. Kompella, and B. Y. Shekunov, Supercritical Fluid Technology for Drug Development, Marcel Dekker, New York, NY, USA, 2004.

[3] E. Reverchon, G. Caputo, S. Correra, and P. Cesti, "Synthesis of titanium hydroxide nanoparticles in supercritical carbon dioxide on the pilot scale," Journal of Supercritical Fluids, vol. 26, no. 3, pp. 253-261, 2003.

[4] G. Caputo, S. Liparoti, R. Adami, and E. Reverchon, "Use of supercritical $\mathrm{CO}_{2}$ and $\mathrm{N}_{2}$ as dissolved gases for the atomization of ethanol and water," Industrial \& Engineering Chemistry Research, vol. 51, no. 36, pp. 11803-11808, 2012.

[5] G. Caputo, R. Adami, and E. Reverchon, "Analysis of dissolvedgas atomization: supercritical $\mathrm{CO}_{2}$ dissolved in water," Industrial \& Engineering Chemistry Research, vol. 49, no. 19, pp. 94549461, 2010.

[6] M. A. Rodrigues, J. Li, L. Padrela, A. Almeida, H. A. Matos, and E. G. de Azevedo, "Anti-solvent effect in the production of lysozyme nanoparticles by supercritical fluid-assisted atomization processes," Journal of Supercritical Fluids, vol. 48, no. 3, pp. 253-260, 2009.

[7] A. M. Hillery, A. W. Lloyd, and J. Swarbrick, Delivery und Targeting, Taylor \& Francis, London, UK, 2001.

[8] I. Smirnova, S. Suttiruengwong, and W. Arlt, "Feasibility study of hydrophilic and hydrophobic silica aerogels as drug delivery systems," Journal of Non-Crystalline Solids, vol. 350, pp. 54-60, 2004.

[9] I. Smirnova, S. Suttiruengwong, M. Seiler, and W. Arlt, "Dissolution rate enhancement by adsorption of poorly soluble drugs on hydrophilic silica aerogels," Pharmaceutical Development and Technology, vol. 9, no. 4, pp. 443-452, 2005.

[10] U. Guenther, I. Smirnova, and R. H. H. Neubert, "Hydrophilic silica aerogels as dermal drug delivery systems-dithranol as a model drug," European Journal of Pharmaceutics and Biopharmaceutics, vol. 69, no. 3, pp. 935-942, 2008.

[11] I. Smirnova, J. Mamic, and W. Arlt, "Adsorption of drugs on silica aerogels," Langmuir, vol. 19, no. 20, pp. 8521-8525, 2003. 
[12] G. Caputo, M. Scognamiglio, and I. De Marco, "Nimesulide adsorbed on silica aerogel using supercritical carbon dioxide," Chemical Engineering Research and Design, vol. 90, no. 8, pp. 1082-1089, 2012.

[13] G. Caputo, I. De Marco, and E. Reverchon, "Silica aerogel-metal composites produced by supercritical adsorption," Journal of Supercritical Fluids, vol. 54, no. 2, pp. 243-249, 2010.

[14] R. E. Treybal, Mass-Transfer Operations, McGraw-Hill, New York, NY, USA, 3rd edition, 1980.

[15] S. Liparoti, R. Adami, G. Caputo, and E. Reverchon, "Supercritical assisted atomization: polyvynilpyrrolidone as carrier for drugs with poor solubility in water," Journal of Chemistry, vol. 2013, Article ID 801069, 5 pages, 2013.

[16] S. Brunauer, L. S. Deming, W. E. Deming, and E. Teller, "On a theory of the van der Waals adsorption of gases," Journal of The American Chemical Society, vol. 62, no. 7, pp. 1723-1732, 1940. 

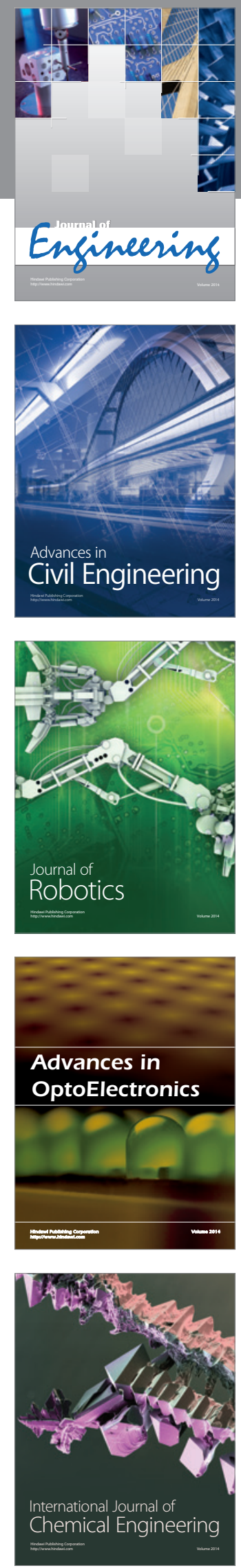

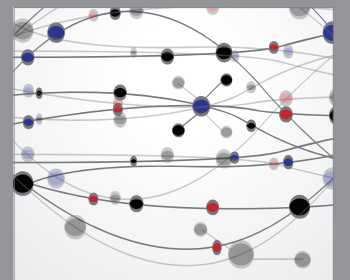

The Scientific World Journal
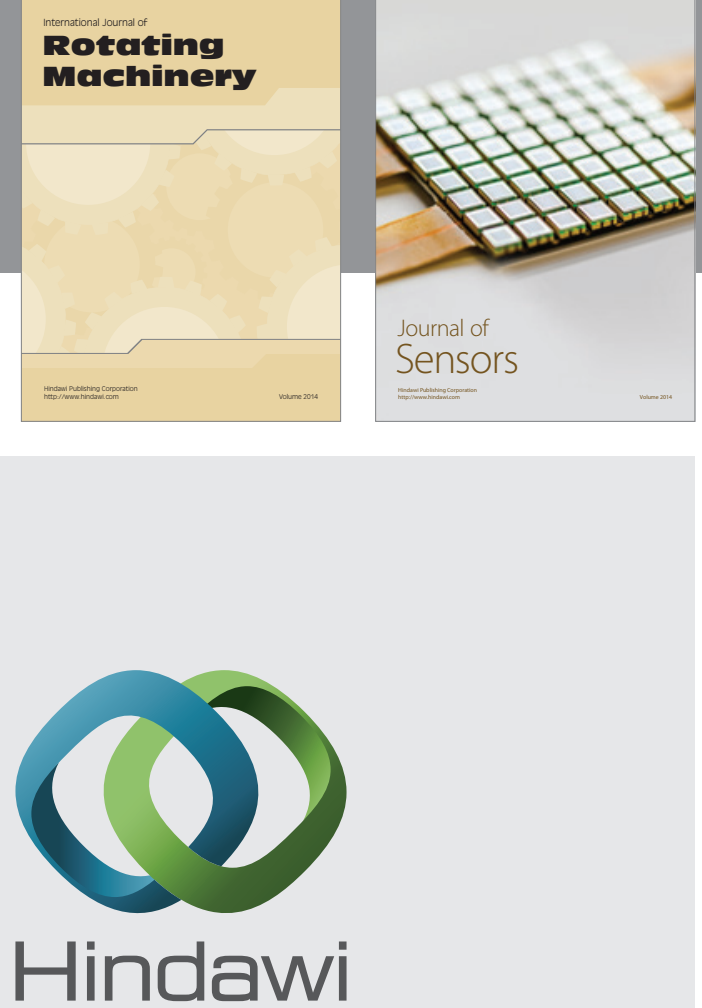

Submit your manuscripts at http://www.hindawi.com
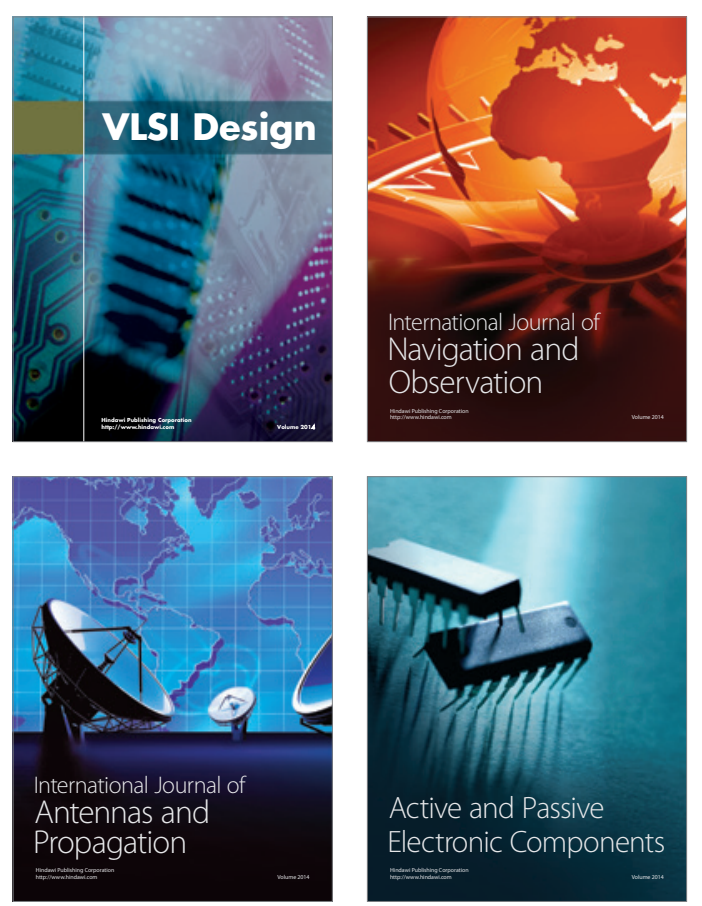
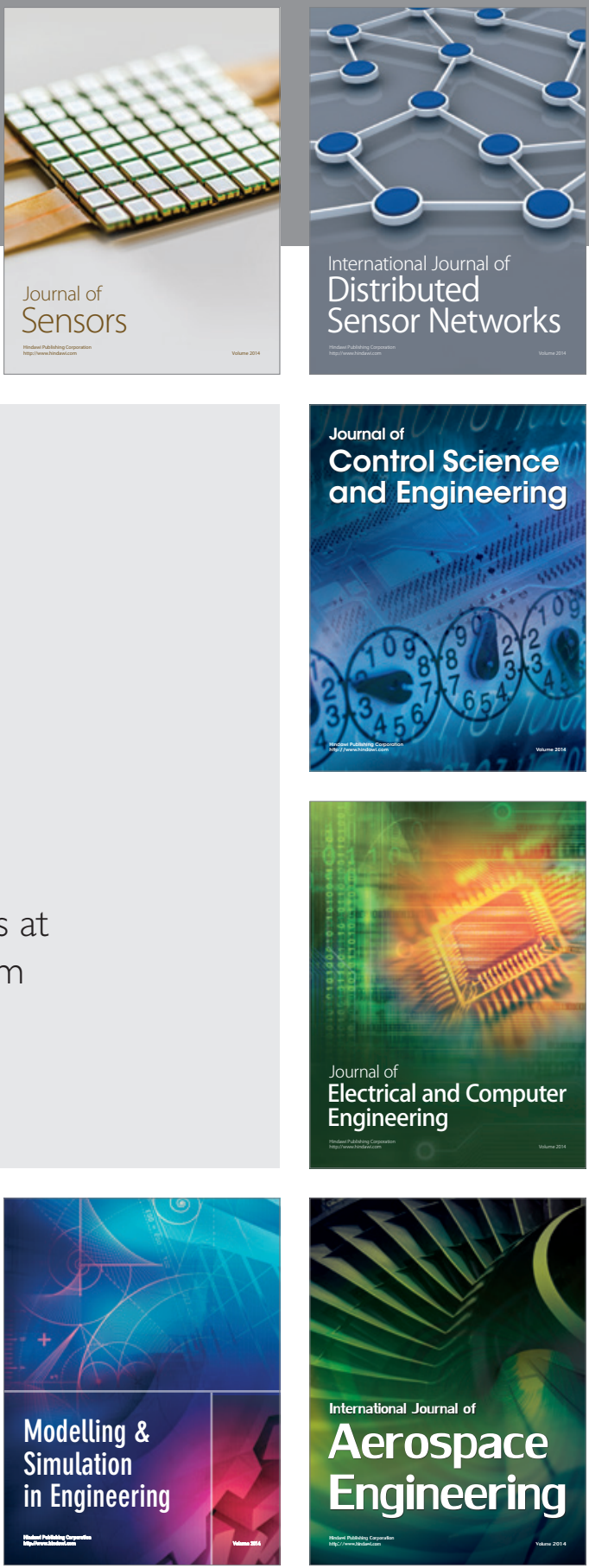

Journal of

Control Science

and Engineering
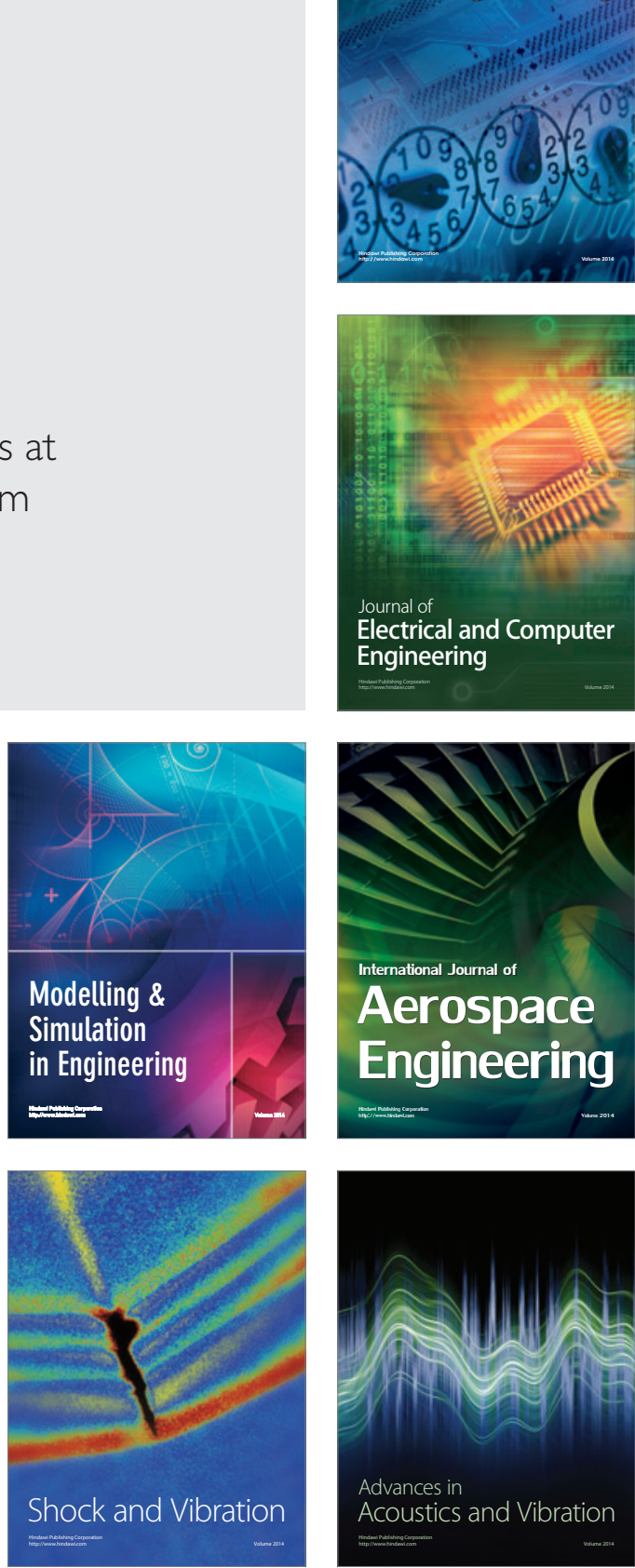